\section{P353 UNIVERSAL IODIZING INITIATIVE OF SALT IN GEORGIA}

Ekaterine Getia*, Teona Iremadze, Ana Pochkhua. LTD 'Imedi clinic', Tbilisi, Georgia

10.1136/archdischild-2019-epa.700

Iodine deficiency is a global health problem and a major cause of mental retardation; More than a billion people are at risk of iodine deficiency in the world. Iodine deficiencies are endemic for Georgia. It is caused by a low level of iodine in water and in soil and therefore in food.

In 1996, was approved the state program for prevention of iodine deficiency, aimed at effective management of iodine defective diseases in Georgia, which reduces them and minimizes .

As a result of this program, distribution of endemic goats decreased among children from 54 to $32.9 \%$ in 1997-2006; The program was canceled in 2007. In 2005 the Parliament of Georgia adopted a new law on the prevention of iodine deficiency in other microelements and vitamins deficiency, according to which the universal iodizing salt of the National Center for Disease Control and Public Health became obligatory and prohibited to import and trade non-iodized salt. The salt iodine standard was established - $40 \pm 15 \mathrm{mg}$ iodine $/ \mathrm{kg}$. For the purpose of dissemination of iodized salt in Georgia and the use of iodine consumption in Georgia, a national research of iodine was conducted in 2017 within the joint project of the National Center for Disease Control and Public Health and UNICEF. The main aim was: what amount of population consumed by iodized salt, how much is the iodine content in the households in salts, the level of iodine in pupils in the urine in the urine concentration and body mass index, determining the level of iodine in pregnant on period of first trimester and so. The results of the study confirmed that more than $90 \%$ of households in Georgia consume the properly iodized salt in all regions .

The quality of iodized salt imported from all major different countries was substantially good; The median concentration of iodine concentrations in urine is within the age group of children $(298 \mu \mathrm{g} / \mathrm{L})(100-299 \mu \mathrm{g} / \mathrm{L})$; In the urine concentration of iodine concentrations in pregnant women $(211 \mu \mathrm{g} / \mathrm{L})$ is within the norm $(150-250 \mu \mathrm{g} / \mathrm{L})$. Which means that Georgia has a sustainable, effective program of universal iodine salt and iodine deficiency is defeated!

Additional monitoring of the use of iodized salt is recommended to ultimately eliminate iodine deficiency and ensure the optimum intake of iodine . the National Center for Disease Control and Public Health of Georgia

\section{P354 CHILD HEALTHCARE MANAGEMENT: THE ROLE OF ART}

Vida Tetteh*, Dominic Kaku. University of Cape Coast, Cape Coast, Ghana

\subsection{6/archdischild-2019-epa.701}

How children experience hospitalization is very different from how an adult experiences hospitalization, and the same child will experience hospitalization differently. There have been efforts by individuals, groups and countries to minimize the detrimental effects and trauma that hospitalization can have on a child. One of the main goals is to normalize the hospital environment. The fight to achieve this has led to the introduction of arts in healthcare to reduce stress and also improve child healthcare. Despite the increasing effort by other countries to inculcate art in healthcare, Ghana seems to have neglected the role that arts play on child healthcare management. There also seem to be no research conducted on the role of art in childcare management in the country. For that matter, the aim of the research was to find out the effects of visual arts on child health care management in some selected hospitals in Ghana.

To achieve the objectives of this study, the following research questions were instrumental:

1. What are the types of visual arts forms used in child healthcare management?

2. What are the perceptions of health personnel on the use of visual arts in child healthcare?

3. What are the benefits of the use of visual arts forms in child healthcare delivery?

The study adopted the descriptive survey design for the study. The study used health personnel at the children hospitals as respondents. A sampling size of 14 health personnel was selected. Descriptive statistics was used to analyse and describe the data collected and that formed the basis of the presentation of findings. The study though had some limitations, is capable of influencing child health care management positively.

The following findings and conclusions were drawn:

1. The types of visual arts forms used in child healthcare management are pictures and drawings on hospital walls, use of cartoons, drawing, painting and beading. The most common one among the hospitals is pictures and drawings on hospital walls.

2. About $43 \%$ of health personnel are not even aware of anything about arts in child healthcare. Health personnel who are aware of it and have observed art therapy before have positive view about the use of Arts (visual art forms) in child healthcare delivery.

3. The use of visual art forms as a form of child healthcare delivery is very beneficial to patients, parents and hospitals

\section{VIDA KORKOR TETTEH}

2019

\section{P355 THE TRANSITION OF CARE FROM ADOLESCENTS TO ADULTS: THE DIABETES MODEL}

Michael Yafi*. UTHealth, The University of Texas Health Science Center at Houston, Houston, USA

10.1136/archdischild-2019-epa.702

Background The transition of diabetes care from adolescents to adult management remains a challenging filed due to many social, demographic and economic factors. During the transition phase, strong emphasis is placed on encouraging teens to begin self-care and self-management of their diabetes through guided practice of physical and practical skills needed for this transition.

Method A registry system and plan were created to transition adolescent patients with both type 1 and 2 diabetes, starting at the age of 16.5 , to adult endocrinology care when the patient turns 18 years old, when graduates from high school 
or if the female patient becomes pregnant at any time during pediatric endocrinology care.

This transition plan includes Identifying and maximizing skills needed for successful self-management of diabetes, identifying barriers to successful transitions, creating a plan of interventions to help and encourage the young adult to continue receiving healthcare, collaborating with the adolescent in locating an adult care endocrinologist who will resume the care, providing teens with discharge of care prescription refills, any supplies needed and school/college instruction packets, and attempt four follow up phone calls to the patient during the transition phase after the patient has been discharged from pediatric care.

Results Out of 160 patients (121 type 1 and 39 type 2 diabetes) who started the transition process with at least one visit completed, only 120 patients (75\%) completed the process and were formally discharged from clinic. The remaining patients $(25 \%)$ are still in the transition phase and currently being seen in clinic. We were able to make follow up appointments with adult endocrinologist for the 120 patients transitioned $(100 \%)$ but only 60 patients documented presence for this follow up (50\%).

Conclusion The outcome of transition of diabetes care was faced by some obstacles; these can be grouped into:

1-Psychological factors: Adolescents burnt out, depression and adjustment disorders. Lack of Independence and readiness.

2-Factors affecting access to health care: Change of health care insurance, lack of insurance, lack of financial means to pay for visit; and transportation problems.

3- Communication factors: Inability to maintain contact after transition (patients not responding to communication from providers, disconnected phone number).

Bridging the gaps in health insurance during this transitional period remains of great importance. Understanding the differences in learning styles between individuals in this transition period will also reflect the readiness for transition.Training health care professionals for this delivery of care is also crucial.

\section{P356 ITALIAN PEDIATRICIANS NEED KNOWLEDGE ABOUT MALTREATMENT AND ABUSE OF CHILDREN. ACTIONS MORE THAN WORDS}

Luigi Nigri*, Paola Mlglioranzi. FIMP (Italian Pediatrician Doctor Federation), Rome, Italy

\subsection{6/archdischild-2019-epa.703}

Italian Medical Doctors do not receive adequate information about the reality of child abuse and maltreatment during their university studies and career, neither during their Specialization in Pediatrics. This lack of knowledge makes it difficult to recognize and to know how to intervene when we are in our own surgeries (if we become general doctors or pediatricians). In 2017 Istat (Italian Institute of Statistics) registered a hundred thousand children mistreated, of which 15 per cent were victims of domestic violence (one out of 5 of the total number of Italian children). The FIMP (Italian Federation of General Pediatricians), the organization which encompasses more than 7 thousand general pediatricians of the country $(80$ per cent), conscious of this difficulty has decided to improve the knowledge of general pediatricians, by organizing one day training session about all the principal types of abuse situations, the symptoms, signs, diagnosis, intervention in case of child abuse and maltreatments. There have been 26 sessions over the last 2 years, all around the country, each with about 50 partecipants and were conducted together with the Italian Society of Pediatricians (SIP). After this first step last June a national study group was instituted, with a national coordinator and one or two representatives for each of the twenty Italian region. This group aims to help spread knowledge about these themes and to create network of cooperation among professionals who take care of children in these situations. Last November the FIMP signed an agreement with the Italian Authority's Guarantor for Children and Adolescents to work together for create a map of every structure dedicated to the care of children and adolescents, such as hospitals, surgeries, health districts, law courts, courts for minors of every town and region, to make it easier for the doctors to intervene, cooperating with professionals in his own reality. The group also has an important role of psychological support of collegues when they feel in doubt or are afraid of intervening. As the International Convention of New York says: to pursue the best interest of the child, even if it is not so simple.

\section{P357 COST-EFFECTIVENESS ANALYSIS FOR TREATMENT OF VISCERAL LEISHMANIASIS IN ARMENIA}

1,2,3 Hripsime Apresyan*, 4,5,6Erik Grigoryan, ${ }^{1}$ Mark Grigoryan, ${ }^{7}$ Edgar Tsarukyan, ${ }^{1,2}$ Vigen Asoyan. 'Y Yerevan State Medical University after Mkhitar Heratsi, Yerevan, Armenia; ${ }^{2}$ Muratsan University Hospital Complex, Yerevan, Armenia; ${ }^{3}$ Wigmore Clinic, Yerevan, Armenia; ${ }^{4}$ Armenian State University of Economics, Yerevan, Armenia; ${ }^{5}$ Swiss UMEF University, Yerevan, Armenia; ${ }^{6}$ Amberd Research Center, Yerevan, Armenia; "Nork" Infectious Clinical Hospital, Yerevan, Armenia

\subsection{6/archdischild-2019-epa.704}

Background The leishmaniases are neglected and poorly reported diseases with underestimated or undetermined incidence in most countries of the WHO European Region. Since the late 1940s, the traditional drugs for VL treatment have been pentavalent antimonials $\left(\mathrm{Sb}^{5+}\right)$.

In the 1980s, conventional amphotericin B deoxycholate (ABD) was introduced, followed by lipid formulations of amphotericin B showing high efficacy and low toxicity. Liposomal amphotericin B (LAB) is a first-line therapy in the WHO European Region, but the price is still very high in Europe as most European countries do not benefit from the preferential price given to WHO for low- and middle-income endemic countries. Duration of treatment with Meglumine antimoniate is minimum 30 days and with $\mathrm{LAB}-\max 7$ days.

Cost-effectiveness ratios derived through cost-effectiveness analysis can be used to compare the efficiency of different health-care programs, although such comparisons should be made cautiously because of the uncertainties associated with many estimates of cost and effectiveness. Armenia is a middleincome country, an endemic region for Visceral Leishmaniasis. Objective The purpose of this study was to evaluate which of $\mathrm{LAB}$ and Meglumine antimoniate treatments is more costeffective in Armenia.

Methods A retrospective economic analysis has been performed to determine the cost-effectiveness of LAB in patients with VL using 24-month data from 'Nork" ICH. The analysis has been conducted from a third-party payer's perspective.

On the basis of historical data average age of patients has been calculated - 24months, with mean weight $11.5 \mathrm{~kg}$. Average daily cost of treatment with LAB has been calculated as 